sis. The dramatic variation in values of creatine kinase activities in case 2 was unexplained. It was not obviously related to varying degrees of exertion before testing. This phenomenon has been described previously and could lead to diagnostic confusion. The condition is generally regarded as inherited on an autosomal recessive basis, but there is evidence to suggest genetic heterogeneity.

These three patients' symptoms, dating from much earlier in childhood, confirm that type $\mathrm{V}$ glycogen storage disease may be diagnosed at an earlier age than often reported. In all three symptoms were related to a disinclination to walk up hills. No more specific symptoms than this occurred within the histories. The test for ischaemic lactate concentration is an important and fairly straightforward procedure that should be considered in a child presenting with any of the features detailed in this report. An earlier diagnosis may be particularly important if the recent preliminary report of improvement in symptoms related to a high protein diet is confirmed in other patients. ${ }^{7}$

We acknowledge the help given by Dr Michael Bennett of the Department of Chemical Pathology, the Children's Hospital, Sheffield, and Dr Andrew Nicol of the Department of Clinical
Chemistry, Glan Clwyd District General Hospital, in the investigations of the patients described and in the preparation of the report.

\section{References}

${ }^{1}$ McArdle B. Myopathy due to a defect in muscle glycogen breakdown. Clin Sci 1951;10:13-35.

${ }^{2}$ Mommaerts WFHM, Illingworth B, Pearson CM, Guillory RJ Seraydarian K. A functional disorder of muscle associated with the absence of phosphorylase. Proc Natl Acad Sci USA $1959 ; 45: 791-7$.

3 Godlewsky HG. Are active and inactive phosphorylase histochemically indistinguishable? $J$ Histochem Cytochem 1963;11:108-12.

${ }^{4}$ Howell RR. Glycogen storage diseases. In: Stanbury JB, Wyngaarden JB, Fredrickson DS, eds. Metabolic basis of inherited disease. New York: McGraw-Hill, 1978;151-3.

5 Ross BD, Radda GK, Gadian DG, Rocker G, Esiri M, Falconer-Smith J. Examination of a case of suspected McArdle's . syndrome by ${ }^{31} \mathrm{P}$ nuclear magnetic resonance. $N$ Engl $J$ Med 1981;304:1338-42.

${ }^{6}$ Ross BD, Radda GK. Application of ${ }^{31} \mathrm{P}$ n.m.r. to inborn errors of muscle metabolism. Biochem Soc Trans 1983;11: 627-30.

7 Slonim AE, Goans PJ. Myopathy in McArdle's syndrome. Improvement with a high-protein diet. $N$ Engl $J$ Med 1985;312:355-9.

Correspondence to Dr Jeff Williams, Glan Clwyd District General Hospital, Bodelwyddan, Rhyl, Clwyd.

Received 23 August 1985

\title{
Eosinophilic gastroenteritis
}

\author{
J Q TROUNCE AND M S TANNER \\ Department of Child Health, University of Leicester
}

\begin{abstract}
SUMMARY We report two children with eosinophilic gastroenteritis - a 14 month old atopic boy with persistent vomiting and aspiration pneumonitis illustrates the mucosal variety of the disorder, and a 9 year old boy with eosinophilic ascites typifies serosal involvement.
\end{abstract}

Eosinophilic infiltration of the gut wall may affect the mucosa, muscularis layer, or the serosa. Each has a distinctly different clinical presentation and the two children we now report illustrate some features of the clinical spectrum.

\section{Case reports}

Case 1. This boy was fully breast fed and thrived until he was 6 months old. Two weeks after introducing cows' milk and various solid foods he developed persistent vomiting and subsequent poor weight gain. Physical examination, chest radiograph, and urine culture were normal. Barium meal at the age of 11 months showed mild gastrooesophageal reflux but no obstruction. Neither milk exclusion nor 'Gaviscon' improved his vomiting. At age 14 months he collapsed after vomiting and at bronchoscopy food material was removed from both $\mathrm{O}$ main bronchi. Mechanical ventilation, together with antibiotics and hydrocortisone, were required to treat his aspiration pneumonitis. On reintroducing a $N$ normal diet, vomiting recurred. Further questioning $\sigma$ revealed two previous episodes of wheeze after $\mathbb{N}$ vomiting and also facial and lip swelling after certain foods (apple, rhubarb, baked beans, and egg). His mother and maternal grandmother have asthma.

A peripheral eosinophilia $\left(3 \cdot 09 \times 10^{9} / 1\right)$ was

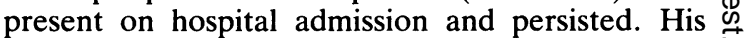
serum IgE concentration was $1890 \mathrm{IU} / 1$ (normal less 0 than 10), and specific IgE antibodies to milk, egg 
white and yolk, wheat, nuts and beans were present. Duodenal biopsy showed a considerable infiltration of eosinophils in the lamina propria, and no parasites.

Vomiting continued despite chlorpheniramine and cimetidine but stopped once a hypoallergenic diet excluding milk, beef, eggs, chicken, salicylates, dyes, and preservatives was introduced. He remains well six months later but challenge with egg induced vomiting, and with milk, vomiting and wheeze.

Case 2. A 9 year old Caucasian boy presented with 10 days' central abdominal pain and distension, and diarrhoea for one day. There was no history of atopy, foreign travel, nor medication except Asilone for two days. His height and weight were on the third centile. Ascites was present and tenderness was detected on deep abdominal palpation.

Investigation showed a peripheral eosinophilia $\left(13.9 \times 10^{9} / 1\right)$. The following tests were normal: blood urea and electrolytes, liver function tests; blood culture; chest radiograph; electrocardiograph; $M$ mode echocardiogram; urine microscopy and culture; urinary vanillyl mandelic acid screen; serum immunoglobulins; and blood T cell, T subset, and B cell numbers. His total IgE concentration was 15 $\mathrm{IU} / \mathrm{ml}$ (normal less than 10), and radioallergosorbent tests to rye grass, house dust mite, aspergillus fumigatus, dog hair, cat fur, milk protein, egg white, fish, and wheat were all negative. Antinuclear factor and autoantibodies to smooth muscle, mitochondria, and parietal cells were absent. Culture for

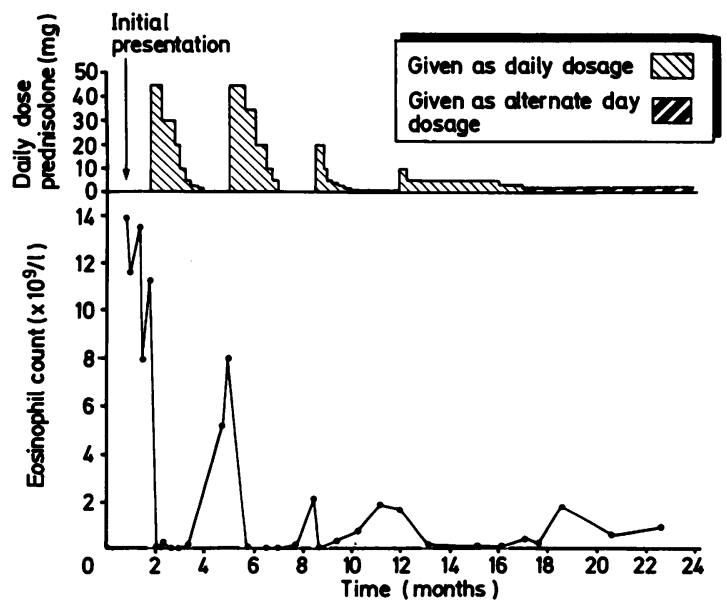

Figure Eosinophil count and steroid dosage in relation to time in case 2. enteric bacteria was negative as were serological tests for aspergillus fumigatus, toxocara, fasciola, yersinia, hydatid, and trichinella. Abdominal ultrasound confirmed ascites; abdominal computed tomogram and barium meal were normal. The ascitic fluid was bloody, rich in eosinophils and protein $(44 \mathrm{gm} / \mathrm{l})$, and sterile on bacterial, tuberculous, and fungal culture. Laparotomy excluded abdominal malignancy but ascites, fibrinous exudate on the serosa, and mesenteric lymph node enlargement were found. Mesenteric node biopsy and bone marrow both showed eosinophilia.

Prednisolone $(2 \mathrm{mg} / \mathrm{kg}$ per day) resulted in rapid resolution of symptoms and ascites. The eosinophil count fell to nil but rose again on stopping treatment (Figure). This and two subsequent relapses showed the need for maintenance steroid treatmentcurrently $5 \mathrm{mg}$ on alternate days.

\section{Discussion}

Eosinophilic gastroenteritis, an infiltration of parts of the gastrointestinal wall with eosinophils and a peripheral blood eosinophilia, was first described by Kaijser in 1937. It affects young adults predominantly, ${ }^{1}$ and is rare in childhood.

Gut involvement is mainly proximal, the clinical features depending on which layer is predominantly affected. Mucosal involvement (33\%) causes vomiting, diarrhoea, and blood loss with resultant anaemia, malabsorption, protein losing enteropathy, and subsequent weight loss or, in children, growth retardation. Infiltration of the muscularis layer $(50 \%)$ results in thickening of the gut wall and subsequent obstruction. Serosal involvement (10 to $20 \%$ ) causes an exudative ascites rich in eosinophils and protein.

Although allergic features occur in less than half of the reported cases, ${ }^{2}$ our first child clearly shows an atopic aetiology. The absence of eczema and staphylococcal skin infection make the hyper-IgE (Job's) syndrome very unlikely. Colon $e^{2} \mathrm{al}^{\mathcal{3}}$ report a boy aged 4 months with pyloric obstruction due to submucosal eosinophilic gastroenteritis. Obstruction was excluded in our patient by barium studies, and his persistent vomiting was probably associated with the duodenitis seen at endoscopy. His presentation with an acute, life threatening respiratory collapse emphasises the need for earlier recognition of this entity.

Indiscriminate use of exclusion diets is to be avoided. Where food antigens are clearly implicated immunologically, however, as in this patient, a strict exclusion diet is indicated. Steroids have been used successfully. ${ }^{1}$ In some cases, especially those with 
atopic features, oral disodium cromoglycate has induced remission. A 16 year old boy with mucosal disease showed no improvement with combined disodium cromoglycate and cimetidine treatment. ${ }^{2}$

The serosal variant, illustrated by case 2 , is rare in childhood but has been reported in an 18 month old boy ${ }^{4}$ and two girls aged 2 years ${ }^{5}$ and 15 years. ${ }^{6}$ The differential diagnosis includes vasculitic disorders such as polyarteritis nodosa, abdominal lymphoma, long term peritoneal dialysis, or rupture of a hydatid cyst. Despite its sinister presentation, it responds readily to steroid treatment, although continued low dosage may be needed to maintain remission as in case 2 .

Eosinophilic gastroenteritis carries a good long term prognosis.

We thank Dr C J F Spry, Dr A C Campbell, and Dr A Edwards of Fisons Ltd for their helpful comments.
References*

' Spry CJF. Eosinophilic gastroenteritis. In: Bouchier IAD, Allan RN, Hodgson HJF, Keighley MRB, eds. Textbook of Gastroenterology. London: Saunders, 1984.

${ }^{2}$ Keshavarzian A, Saverymuttu SH, Tai P-C, et al. Activated eosinophils in familial eosinophilic gastroenteritis. Gastroenterology 1985;88:1041-9.

${ }^{3}$ Colon AR, Sorkin LF, Stern WR, Lessinger VS, Hefter LG, Hodin E. Eosinophilic gastroenteritis. J Pediatr Gastroenterol Nutr 1983;2:187-9.

${ }^{4}$ Shioda H, Ikeda K, Mishima K. Eosinophilic peritonitis in a child. Clin Pediatr 1970;9:120-1.

${ }^{5}$ Kravis LP, South MA, Rosenlund ML. Eosinophilic gastroenteritis in the pediatric patient. Clin Pediatr 1982;21:713-7.

${ }^{6}$ Hunt CE, Papermaster TC, Nelson EN, Krivit W. Eosinophilic peritonitis. Report of two cases. Journal-Lancet 1967;87:473-6.

${ }^{*}$ Additional references are available on request from the authors.

Correspondence to Dr M S Tanner, Department of Child Health, Leicester Royal Infirmary, Leicester LE1 5WW.

Received 15 July 1985

\section{Are Tanner growth charts applicable to children at school entry in Leeds?}

\section{J M H BUCKLER}

\section{University Department of Paediatrics and Child Health, The Generat Infirmary at Leeds}

\begin{abstract}
SUMMARY Analysis of the heights and weights of about $85 \%$ of school entrants in Leeds in 1982 and 1983 showed that the distribution at a mean of $5 \cdot 3$ years is similar to the accepted standard centiles and confirms the appropriateness of the use of these standards at this age.
\end{abstract}

There has been much emphasis recently on the need for the screening of heights of schoolchildren to identify at an early stage those whose heights are outside the accepted normal range so that, where appropriate, investigation can be undertaken and treatment begun.

We are dependent in all methods of screening heights and weights on the availability of appropriate standards. Standards for children of different ethnic origins or in different parts of the country may possibly vary. Eveleth and Tanner $^{1}$ and Marshall ${ }^{2}$ reported in detail population variations on the basis of many references. The former showed that at 4 years of age there is a range between the tallest and shortest European populations of $4 \mathrm{~cm}$ in mean height for boys and girls and $1.2 \mathrm{~kg}$ in mean weight for boys and $1.5 \mathrm{~kg}$ for girls. The changes were largely attributed to environmental causes but partly also to genetic causes. It is, however, difficult to define the relative importance of these factors. Marshall reported a $7 \mathrm{~cm}$ difference in stature of 6 year olds from the studies of four different ethnic groups of supposedly good socioeconomic backgrounds, but commented that this did not necessarily imply the same level of health and nutrition in all cultures. ${ }^{2}$ There are, however, few observations on growth variables of children of different ethnic origins brought up in Britain or in different environments within this country. Goel et al studied the growth of immigrant children in Glasgow, comparing Asian, African, Chinese, and Scottish children, and found that Africans were tallest and Scottish and Chinese were shortest, and also that Africans were heavier than other groups. ${ }^{3}$ Children born in Scotland were taller than those born in their country of origin, but, surprisingly, social class, living conditions, and diet bore little relation to growth. Arguably, from a screening point of view such minor differences do not matter, but nevertheless it seemed of value to examine the distribution of measurements of schoolchildren in a northern 